\title{
Produção de manga sob diferentes regimes de irrigação, em condições subúmidas ${ }^{1}$
}

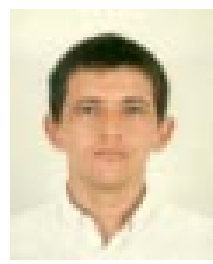

Francisco das C. Oliveira ${ }^{2}$, Eugênio F. Coelho ${ }^{3}$, Lúcio F. L. Vasconcelos ${ }^{4}$ \& Eugênio C. E. Araújo ${ }^{4}$

1 Extraído da Dissertação de Mestrado do $1^{\circ}$ autor, apresentada à UFBA. Trabalho financiado pelo PADCT III - FINEP

2 Embrapa Semi-Árido, Transferência de Tecnologias. BR 122, km 50, CP 23, CEP 56300-000, Petrolina, PE. Fone: (87) 3862-2845. E-mail: oliveira@cpatsa.embrapa.br (Foto)

${ }^{3}$ Embrapa Mandioca e Fruticultura, Cruz das Almas, BA. Fone: (75) 6721-2120. E-mail: coelho@cnpmf.embrapa.br

${ }^{4}$ Embrapa Meio-Norte. Av. Duque de Caxias 5650, B. Buenos Aires, CEP 64006-240, Teresina, PI. Fone: (86) $225-1141$. E-mail: lucio@cpamn.embrapa.br

Protocolo $54-24 / 4 / 2002$

\begin{abstract}
Resumo: Este trabalho teve como escopo definir uma estratégia de manejo eficiente da irrigação que permita a maximização da produção da cultura da manga, combinada com o uso mais eficiente, racional e sustentável da água. Os trabalhos foram desenvolvidos em área da empresa Mangal Frutas Tropicais de Exportação Ltda, situada no km 35 da rodovia Teresina - Palmeirais, PI. O delineamento experimental utilizado foi em blocos casualizados, com seis tratamentos (seis regimes de irrigação) e quatro repetições, com a parcela experimental composta de quatro plantas. Os tratamentos, depois de estabelecidos, apresentaram-se da seguinte maneira: sem irrigação e com irrigação de $0,44,0,55,0,86,1,00$ e 1,37 da evapotranspiração de referência (ETo) determinada a partir da evaporação do tanque "Classe A". Foram avaliados os componentes de produção (produtividade, peso e número de frutos por planta). O teor de água do solo foi monitorado usando-se uma sonda de nêutrons, através de tubos de acesso de PVC de $60 \mathrm{~mm}$ de diâmetro, instalados a 1,0 m da planta, nas profundidades de 0,3;0,5 e 0,7 m, para os seis regimes de irrigação em todos os blocos. As leituras das umidades foram feitas antes da irrigação, duas vezes por semana. O máximo rendimento comercial estimado $\left(12,491 \mathrm{t} \mathrm{ha}^{-1}\right)$ foi obtido com uma lâmina total de irrigação no período produtivo de $601,05 \mathrm{~mm}$.
\end{abstract}

Palavras-chave: Mangifera indica L., manejo de irrigação, evapotranspiração

\section{Mango yield under different irrigation regimes in subhumid conditions}

\begin{abstract}
The purpose of this study was to define a strategy of efficient irrigation water management to allow maximization of mango crop yield. This goal was sought to obtain irrigation sustainability, by means of an efficient use of water for this crop. The experiment was carried out at Mangal - Frutas Tropicais de Exportação Limited farm, located at $35 \mathrm{~km}$ on Teresina - Palmeirais highway, in the State of Piaui. The experiment followed a random block design with six treatments and four replications. The treatments were: no irrigation, irrigation depth equivalent to $0.44,0.55,0.86,1.00$ and 1.37 of ETo, determined by using Class $A$ pan evaporation. The variables evaluated were: productivity, weight and number of fruits per plant. Soil water content was monitored using neutron probe in $60 \mathrm{~mm}$ PVC tubes, installed at a distance of $1,0 \mathrm{~m}$ from trunk at depths of $0.3 ; 0.5$ and $0.7 \mathrm{~m}$ for the six irrigation regimes in all blocks. Soil water content was measured twice a week, before irrigation. Estimated maximum commercial yield $\left(12.491 \mathrm{t} \mathrm{ha}^{-1}\right)$ was obtained for the water depth of $601.05 \mathrm{~mm}$.
\end{abstract}

Key words: Mangifera indica L., irrigation management, evapotranspiration

\section{INTRODUÇÃO}

O Brasil vem se destacando como um dos maiores produtores de frutas tropicais do mundo, devido às condições ambientais adequadas para o desenvolvimento dessas espécies frutíferas, dentre as quais se destaca a manga (Mangifera indica $\mathrm{L}$.) que vem apresentando uma grande demanda interna, com projeções de aproximadamente 900,5 mil toneladas para o ano de 2020 (CODEVASF, 1989). Esta frutífera tem, também, aceitação em escala crescente no mercado internacional, tornando-se, desta forma, um atraente investimento comercial.

O Nordeste apresenta-se como a principal região produtora de manga no Brasil. Uma parte significativa desta produção encontra-se no Estado do Piauí, onde a microrregião de Teresina 
detém $30 \%$ da área plantada tornando-se, assim, o maior e o mais importante pólo de cultivo de manga da região MeioNorte (Nordeste Ocidental) do Brasil, e um dos principais da região Nordeste (Vasconcelos et al., 1998).

Apesar da alta tecnologia aplicada a esta cultura, os conhecimentos das suas necessidades hídricas são escassos para aquela região. As poucas informações existentes são oriundas principalmente da região semi-árida do Nordeste, cujas condições climáticas são diferentes das observadas na região Meio-Norte. O manejo da irrigação não tem encontrado critérios ou bases técnicas e, portanto, tem sido de natureza empírica.

As informações sobre a irrigação da cultura da manga ainda são bastante preliminares no Brasil como em outras regiões produtoras no mundo. A maior disponibilidade dessas informações reside na escolha do método de irrigação e na época de aplicação e suspensão de água (Cunha et al., 1994; Póvoa, 1996; Soares \& Costa, 1995; Coelho et al., 2000).

Os métodos mais comuns e práticos de manejo da irrigação da cultura da manga são aqueles em função da água disponível do solo, da definição da irrigação baseada no monitoramento do potencial de água do solo, por meio de tensiômetros, e o da irrigação fundamentado na evapotranspiração de referência obtida pelo método de Penman-Monteith, modificado pela FAO (Jensen et al., 1989) ou pelo tanque "Classe A". No primeiro caso, as informações existentes provêm de Azzouz et al. (1977) que, verificando efeito da freqüência de irrigação na produtividade e qualidade da cultura da mangueira, obtiveram os melhores resultados para um teor de água no solo correspondente a $33 \%$ da disponibilidade de água durante o período crítico (floração à colheita) e $66 \%$ da disponibilidade de água no restante do ano. Soares \& Costa (1995) recomendaram que as irrigações sejam feitas quando o teor de água do solo atingir $50 \%$ da água disponível. No segundo caso, as únicas informações são fornecidas por Soares \& Costa (1995) que sugeriram tensões de água no solo entre 15 e $25 \mathrm{kPa}$ em solo arenoso, podendo alcançar de 40 a $60 \mathrm{kPa}$ em solo argiloso.

O manejo da irrigação pelo método do tanque "Classe A" tem sido amplamente utilizado em todo o mundo. Isso se deve principalmente aos resultados satisfatórios alcançados para a estimativa das necessidades hídricas das culturas, a custo relativamente baixo, possibilidade de instalação próximo da cultura a ser irrigada e à facilidade de operação (Volpe \& Churata-Masca, 1988).

Este trabalho teve como objetivo definir uma estratégia de manejo eficiente da irrigação que permita a maximização da produção da cultura da manga em seu início, possibilitando um uso mais eficiente, racional e sustentável da água nas condições edafoclimáticas do Meio-Norte do Brasil.

\section{MATERIAL E MÉTODOS}

O experimento foi desenvolvido em área da empresa Mangal Frutas Tropicais de Exportação Ltda, de latitude 5’ 5' Sul, longitude $42^{\circ} 48^{\prime}$ Oeste e altitude $74,4 \mathrm{~m}$, no $\mathrm{km} 35$ da rodovia Teresina - Palmeirais, PI, em 1999. A área plantada é de 150 ha de manga da variedade Tommy Atkins, enxertada sobre o portaenxerto da variedade "Fiapo", com quatro anos de idade, em espaçamento de 7 x 9 m e irrigada por microaspersão.

O solo da área é um Podzólico Vermelho-amarelo, apresentando as características físico-hídricas mostradas na Tabela 1. A Figura 1 apresenta a curva característica de água no solo, referente à profundidade de 0 - 0,40 m, ajustada com uso do modelo não linear de van Genuchten (1980) conforme Coelho et al. (2000) em que $\theta_{\mathrm{s}}$ é a umidade de saturação e $\theta_{\mathrm{r}}$ é a umidade residual.

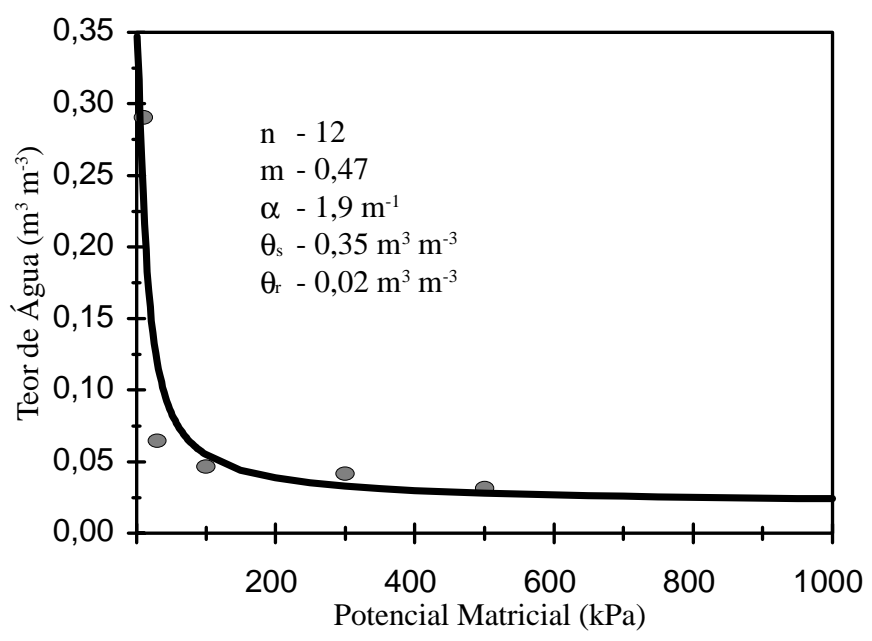

Figura 1. Curva característica de retenção de água do solo da área experimental e parâmetros da equação de van Genuchten (1980)

O clima da região, segundo a classificação de Köppen, é do tipo Aw' (tropical subúmido quente). As médias anuais dos dados climáticos referentes a 1999, ano de realização do experimento, apresentaram-se da seguinte maneira: temperatura $27,5^{\circ} \mathrm{C}$; umidade relativa $74,62 \%$; precipitação pluvial $1654 \mathrm{~mm}$; insolação $7,73 \mathrm{~h} \mathrm{~d}^{-1}$; velocidade dos ventos $1,4 \mathrm{~m} \mathrm{~s}^{-1}$ e evaporação $6,12 \mathrm{~mm} \mathrm{~d}^{-1}$.

A precipitação pluviométrica ocorrida na região no ano de 1999 (1654 mm) foi muito acima da média histórica, que é de $1360 \mathrm{~mm}$ (SUDENE, 1990).

Dentro do período estudado, as adubações de manutenção e produção foram divididas em três etapas onde, também, foram feitas aplicações dos seguintes produtos, com suas respectivas quantidades por planta: a) adubação pós-colheita (safra anterior): $30 \mathrm{~kg}$ de esterco, $1,5 \mathrm{~kg}$ de calcário, $3 \mathrm{~kg}$ de gesso, $1 \mathrm{~kg}$ de superfosfato simples, $200 \mathrm{~g}$ de ácido fosfórico, $150 \mathrm{~g}$ de FTE Br 12, $220 \mathrm{~g}$ de uréia, $200 \mathrm{~g}$ de sulfato de potássio e $300 \mathrm{~g}$ de sulfato de magnésio; b) adubação pós-florada: $300 \mathrm{~g}$ de nitrato de cálcio, 292 g de MAP, $198 \mathrm{~mL}$ de ácido fosfórico, $80 \mathrm{~mL}$

Tabela 1. Características físico-hídricas do solo da área experimental

\begin{tabular}{|c|c|c|c|c|c|c|c|}
\hline \multirow{3}{*}{$\begin{array}{l}\text { Profundidade } \\
\text { (m) }\end{array}$} & \multicolumn{2}{|c|}{ Areia } & \multirow{3}{*}{ Silte } & \multirow{3}{*}{ Argila } & \multirow{3}{*}{$\begin{array}{l}\text { Densidade } \\
\mathrm{kg} \mathrm{dm}^{-1}\end{array}$} & \multirow{2}{*}{\multicolumn{2}{|c|}{$\begin{array}{l}\text { Umidade } \\
\left(\mathrm{m}^{3} \mathrm{~m}^{-3}\right)\end{array}$}} \\
\hline & Grossa & Fina & & & & & \\
\hline & \multicolumn{2}{|c|}{$\mathrm{g} \mathrm{kg}^{-1}$} & & & & $10 \mathrm{kPa}$ & $1500 \mathrm{kPa}$ \\
\hline $0,00-0,30$ & 210 & 530 & 190 & 70 & 1,66 & 0,29 & 0,03 \\
\hline $0,30-0,50$ & 200 & 540 & 190 & 70 & 1,71 & 0,24 & 0,03 \\
\hline $0,50-0,70$ & 150 & 430 & 160 & 260 & 1,77 & - & - \\
\hline
\end{tabular}


de ácido bórico, $120 \mathrm{~g}$ de sulfato de zinco, $422 \mathrm{~g}$ de sulfato de potássio, $99 \mathrm{~g}$ de nitrato de potássio, $300 \mathrm{~g}$ de sulfato de magnésio e $244 \mathrm{~g}$ de cloreto de cálcio; c) adubação de crescimento de frutos: $300 \mathrm{~g}$ de nitrato de cálcio, $400 \mathrm{~g}$ de MAP, $360 \mathrm{~mL}$ de ácido fosfórico, $80 \mathrm{~mL}$ de ácido bórico, $120 \mathrm{~g}$ de sulfato de zinco, $422 \mathrm{~g}$ de sulfato de potássio, $300 \mathrm{~g}$ de nitrato de potássio, $300 \mathrm{~g}$ de sulfato de magnésio e $244 \mathrm{~g}$ de cloreto de cálcio.

A limpeza da área foi realizada a cada $60 \mathrm{~d}$, através da aplicação de herbicidas na projeção da copa e roço nas entrelinhas, além da poda de limpeza, para retirada de restos de panículas, $15 \mathrm{~d}$ antes da aplicação do retardante de crescimento.

O delineamento experimental foi em blocos casualizados, com seis tratamentos (seis níveis de água) e quatro repetições, em quatro fileiras de plantas, cada fileira com 24 plantas. A parcela experimental foi composta de quatro plantas numa fileira, sendo as duas plantas externas tomadas como bordaduras e as duas internas como úteis, perfazendo o total de 48 plantas úteis. Os tratamentos, depois de estabelecidos, com base da ETo mensurada a partir da evaporação do tanque "Classe A", apresentaram-se da seguinte maneira: sem irrigação, $0,44,0,55,0,86,1,00$ e 1,37 ETo. Para a diferenciação dos tratamentos, usaram-se microaspersores com vazões diferentes entre tratamentos $\left(20,30,41,53\right.$ e $\left.60 \mathrm{~L} \mathrm{~h}^{-1}\right)$ operando sob a mesma pressão de serviço usada no sistema de irrigação $(160 \mathrm{kPa})$.

O experimento foi avaliado de janeiro a dezembro de 1999. A irrigação iniciou-se logo após a interrupção do estresse hídrico imposto à cultura propositadamente, para fins de indução da floração depois do término das precipitações pluviométricas e totalizou o período de $82 \mathrm{~d}$. O processo de indução floral da mangueira iniciou-se com a aplicação do retardante de crescimento Paclobutrazol (Cultar) via solo, na dosagem de $1 \mathrm{~g}$ do princípio ativo por metro linear de copa, no início de fevereiro (5/2/1999), associado a um estresse hídrico, para promover a paralisação do crescimento. A quebra de dormência das gemas foi feita por meio de três aplicações com nitratos, em intervalos de 7 d, a primeira no dia 16/7/1999, com nitrato de potássio $\left(\mathrm{KNO}_{3}\right)$ na concentração de 4\%; a segunda, no dia 23/7/1999, com nitrato de cálcio - $\mathrm{Ca}\left(\mathrm{NO}_{3}\right)_{2}$ na concentração de $2,5 \%$ e a terceira, no dia 30/7/1999, com $\mathrm{KNO}_{3}$ na concentração de 3\%. Após o florescimento, deu-se início às irrigações (15/8/1999).

Logo após, as irrigações diferenciadas foram seguidas, como se previu em função dos regimes impostos, correspondendo o período de aplicação de água de 15 de agosto a 17 de novembro de 1999, compreendendo os estádios entre a abertura das flores e a colheita.

A quantidade de água aplicada diariamente foi calculada considerando-se a percentagem da evapotranspiração diária da cultura, definida para cada tratamento com base nos valores de Kc, sugeridos por Soares \& Costa (1995) recomendados para citros, multiplicados pela evapotranspiração de referência diária estimada a partir do tanque "Classe A". A lâmina total necessária, ou lâmina bruta foi calculada pela equação (Keller \& Bliesner, 1992):

$$
\operatorname{LTN} \frac{0,1 \sqrt{\mathrm{A}_{\mathrm{s}}} \quad \mathrm{ET}_{\mathrm{c}} \quad \mathrm{P}_{\mathrm{e}}}{\mathrm{E}_{\mathrm{a}}}
$$

em que:

LTN - lâmina total necessária, mm

$\mathrm{A}_{s}$ - percentagem da área de ocupação da planta sombreada, decimal

$\mathrm{ET}_{\mathrm{c}}$ - evapotranspiração da cultura, $\mathrm{mm}$

$\mathrm{P}_{\mathrm{e}} \quad$ - precipitação efetiva, $\mathrm{mm}$

$\mathrm{E}_{\mathrm{a}} \quad$ - eficiência de aplicação, decimal

A precipitação efetiva foi assumida como a precipitação pluviométrica total. O valor de $\mathrm{A}_{\mathrm{s}}$ foi de $45 \%$ durante os estádios avaliados. O valor da eficiência de aplicação utilizado foi de $85 \%$. O controle das irrigações foi feito usando-se um programa de computador, cujos parâmetros de entrada foram, basicamente, a data, a evaporação do tanque "Classe A", a precipitação e a percentagem de recobrimento da cultura. Para efeito de paralisação do crescimento da cultura, após o final do período chuvoso (maio) estabeleceu-se um período de estresse hídrico de 82 d, em função do qual a irrigação só foi iniciada em agosto, quando as plantas já estavam floradas. De janeiro a maio não houve necessidade de irrigação, devido às chuvas que ocorreram nesse período.

O teor de água do solo foi monitorado usando-se uma sonda de nêutrons em 20 tubos de acesso de PVC de $60 \mathrm{~mm}$ de diâmetro, sendo cinco tubos em cada bloco, instalados a $1 \mathrm{~m}$ da planta, nas profundidades de 0,3,0,5 e 0,7 m, para os seis regimes de irrigação em todos os blocos. As leituras da umidade do solo foram realizadas antes da irrigação, duas vezes por semana.

A colheita foi realizada em novembro de 1999, compreendendo um período de três semanas. Avaliaram-se os seguintes componentes de produção: produtividade, número de frutos por planta, peso de frutos por planta e peso médio de frutos.

Os frutos foram colhidos, pesados, contados e classificados, considerando-se a classificação adotada pelo produtor: frutos tipo 7, com peso acima de $560 \mathrm{~g}$; frutos tipo 8 , com peso de 480 a $560 \mathrm{~g}$; frutos tipo 9 , com peso de 420 a $480 \mathrm{~g}$; frutos tipo 10 , com peso de 375 a $420 \mathrm{~g}$; frutos tipo 12, com peso de 335 a $375 \mathrm{~g}$; frutos tipo 14, com peso de 285 a $335 \mathrm{~g}$; frutos tipo 16 , com peso de $240 \mathrm{a} 285 \mathrm{~g}$ e frutos refugos, com peso abaixo de $240 \mathrm{~g}$.

\section{RESULTADOS E DISCUSSÃO}

\section{Lâmina d'água aplicada}

Na Tabela 2 encontram-se as quantidades de água aplicada na área experimental, via irrigação, durante o período produtivo da cultura (agosto a novembro) e a precipitação pluviométrica, durante todo o período produtivo. Os valores das lâminas totais de irrigação aplicadas variaram de $193,9 \mathrm{~mm}$ no regime de 0,44 ETo a 601,05 mm no regime de 1,37 ETo, sendo esta 3,1 vezes superior à primeira, evidenciando ampla variação nos teores de água disponível no solo às plantas. Quando se analisam os regimes totais aplicados durante o período de diferenciação dos tratamentos, observa-se que as irrigações participaram com $0 ; 53,9 ; 59,3 ; 69,5 ; 72,4$ e 78,4\% das lâminas totais aplicadas no período produtivo, respectivamente, para os tratamentos sem irrigação, 0,44, 0,55, 0,86, 1,00 e 1,37 da ETo. 
Tabela 2. Lâminas de água aplicadas por tratamento e precipitação ocorridas, durante o período de execução do experimento em 1999

\begin{tabular}{crcc}
\hline \multirow{2}{*}{ Tratamento } & \multicolumn{2}{c}{ Lâmina $(\mathrm{mm})$} & \\
\cline { 2 - 3 } & Irrigação & $\begin{array}{c}\text { Precipitação } \\
\text { Total }\end{array}$ & Total $(\mathrm{mm})$ \\
\hline Sem irrigação & 0,00 & 1654 & 1654,00 \\
0,44 ETo & 193,89 & 1654 & 1847,89 \\
0,55 ETo & 242,36 & 1654 & 1896,36 \\
0,86 ETo & 378,08 & 1654 & 2032,08 \\
1,00 ETo & 436,24 & 1654 & 2090,24 \\
1,37 ETo & 601,05 & 1654 & 2255,05 \\
\hline
\end{tabular}

Na Figura 2 visualizam-se as lâminas aplicadas diariamente por tratamento, relativas às irrigações realizadas. Observou-se que houve diferenciação entre as lâminas, sendo aquelas referentes aos tratamentos 0,44 e 0,55 ETo muito próximas. $\mathrm{O}$ mesmo também ocorreu para os tratamentos 0,86 e 1,0 ETo. A diferença média entre as lâminas aplicadas nos tratamentos 0,44 e 0,55 ETo foi de $25 \%$. A diferença média entre as lâminas aplicadas nos tratamentos 0,55 e 0,86 ETo foi de $56 \%$, tendo sido de $16 \%$ entre os tratamentos 0,86 e 1,0 ETo e de $37 \%$ entre 1,0 e 1,37 ETo.

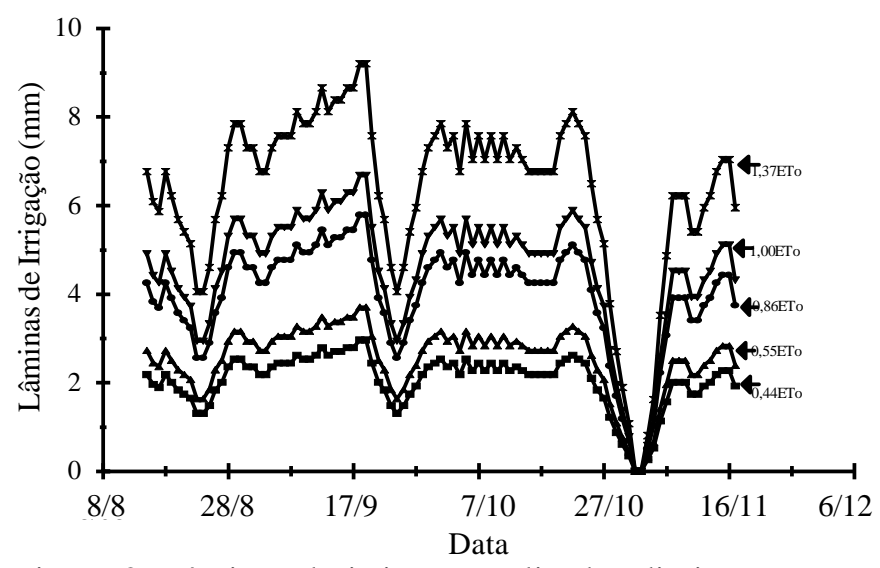

Figura 2. Lâminas de irrigação aplicadas diariamente nos diferentes regimes hídricos propostos para a cultura da manga

\section{Estado da água no solo}

Os teores de água a 0,30, 0,50 e 0,70 $\mathrm{m}$ de profundidade, mostrados na Figura 3 (A., B e C) refletem o efeito dos diferentes regimes de irrigação aplicados durante o ano.

Observa-se que a umidade no solo referente a todos os tratamentos, dentro do período chuvoso (janeiro a abril) para as profundidades de 0,30 e 0,50 m, manteve com teores de água inferiores e próximos à capacidade de campo, decaindo a partir do mês de maio até o início de agosto. Esta redução de umidade resultou num período de estresse hídrico provocado propositadamente, com a finalidade de promover uma intensidade maior na floração. Os valores de umidade do solo foram próximos e superiores ao ponto de murcha para a profundidade de $0,30 \mathrm{~m}$, mas inferiores a $65 \%$ da umidade à capacidade de campo, para a profundidade de $0,50 \mathrm{~m}$. O mesmo não aconteceu para a profundidade de $0,70 \mathrm{~m}$, em que a umidade do solo se manteve em torno e um pouco acima da capacidade de campo, permanecendo inferior a esse valor somente no

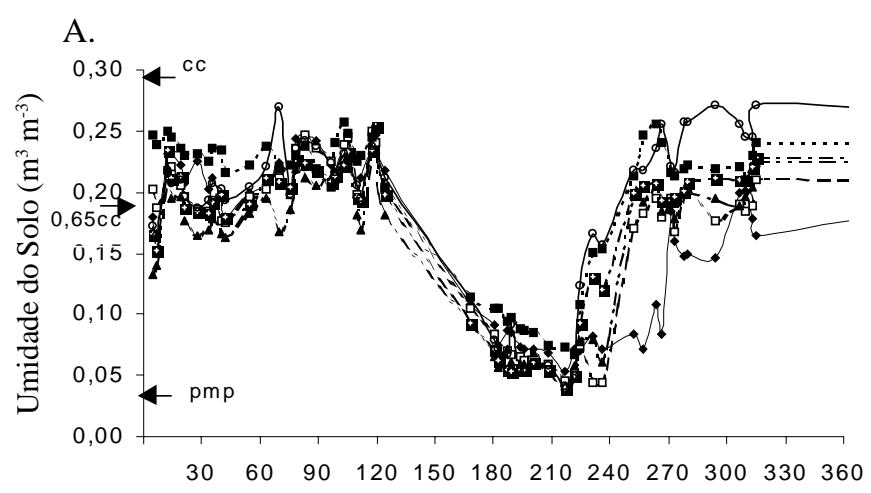

B.
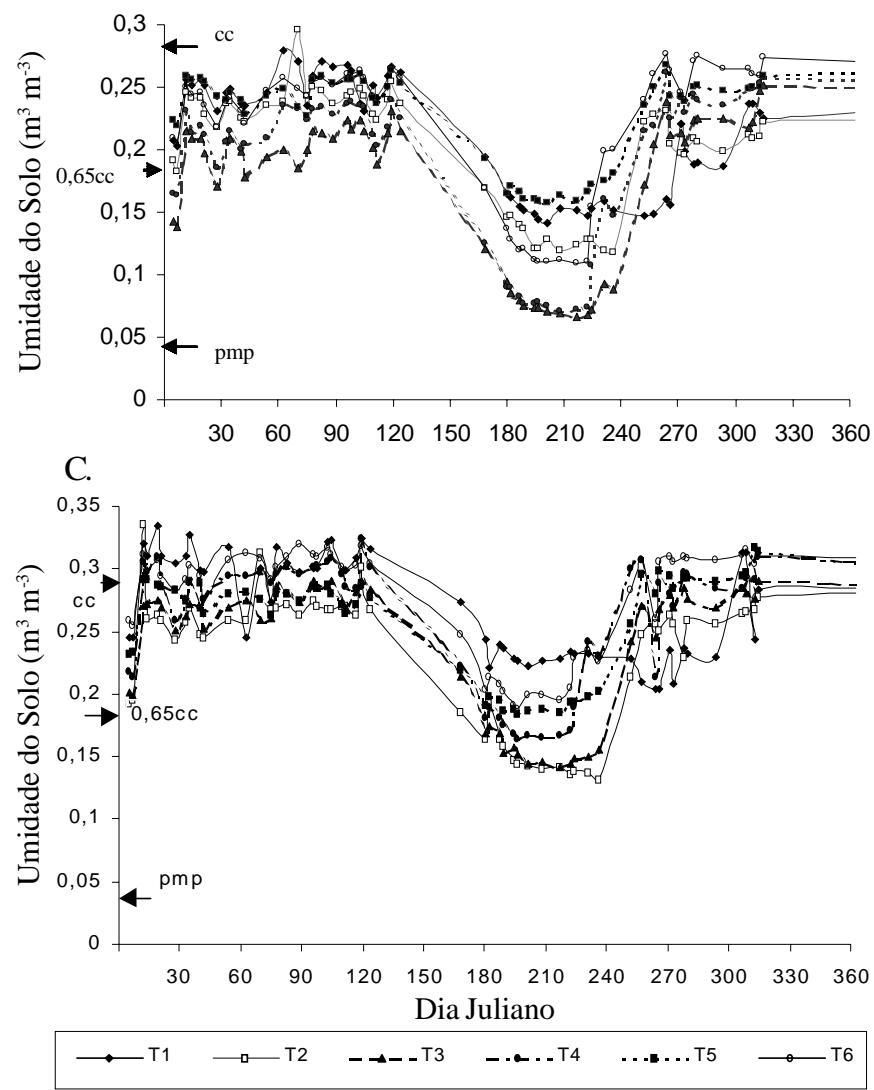

Figura 3. Variação da umidade do solo na profundidade de 0,30 (A), 0,50 (B) e 0,70 m (C), referente à aplicação dos regimes de irrigação ropostos durante o ano de 1999

período de estresse hídrico, mas com valores acima de $65 \%$ da capacidade de campo. Deste ponto em diante, ou seja, após o final do estresse hídrico ( 15 de agosto) iniciaram-se as irrigações e a umidade do solo voltou a subir gradativamente até a capacidade de campo. A partir desse ponto, a umidade do solo permaneceu próxima e abaixo da capacidade de campo, havendo acréscimo nos teores de umidade proporcionalmente aos regimes aplicados. O tratamento que não recebeu irrigação, a umidade do solo decresceu e atingiu teores de água menores que nos demais tratamentos favorecidos com irrigação, nas três profundidades avaliadas $(0,3,0,5$ e $0,7 \mathrm{~m})$.

Na profundidade de $0,3 \mathrm{~m}$ (Fig. 3A), observou-se a maior diferença no comportamento da umidade no solo entre a situação irrigada e a não-irrigada, diminuindo à medida em que aumentou a profundidade. Esses resultados mostram que o 
Tabela 3. Resumo da análise de variância para as variáveis produtividade total (PT) e comercial (PC), número total de frutos por planta

(NTF), número de frutos comerciais por planta (NFC), peso total de frutos por planta (PTF) e peso de frutos comerciais por planta (PFC)

\begin{tabular}{|c|c|c|c|c|c|c|}
\hline \multicolumn{7}{|c|}{ Q.M. } \\
\hline \multirow{2}{*}{$\begin{array}{c}\text { Causas de } \\
\text { Variação }\end{array}$} & PT & $\mathrm{PC}$ & \multirow{2}{*}{ NTF } & \multirow{2}{*}{ NFC } & PTF & PFC \\
\hline & & & & & \multicolumn{2}{|c|}{$(\mathrm{kg})$} \\
\hline Regimes & $60,73^{* *}$ & $43,57^{* *}$ & $26697,29^{* * *}$ & $15600,29^{* *}$ & $2410,56^{* *}$ & $1729,50^{* * *}$ \\
\hline Bloco & $8,11 \mathrm{~ns}$ & $10,49 \mathrm{~ns}$ & $1980,63 \mathrm{~ns}$ & $2922,92 \mathrm{~ns}$ & $321,75 \mathrm{~ns}$ & $16,53 \mathrm{~ns}$ \\
\hline Resíduo & 10,47 & 8,48 & 4375,16 & 2884,97 & 415,78 & 336,68 \\
\hline CV $(\%)$ & 29,33 & 29,25 & 30,00 & 29,00 & 29,33 & 29,25 \\
\hline
\end{tabular}

** Significativo em nível de $1 \%$ de probabilidade; ns - Não significativo

tempo com ausência de irrigação foi insuficiente para a promoção do estresse hídrico da planta, uma vez que na profundidade de $0,70 \mathrm{~m}$ e, possivelmente, abaixo desse ponto, os níveis de umidade estão próximos ou acima de $65 \%$ da capacidade de campo, o que implica em absorção de água pelas raízes nessas profundidades.

\section{Produção e componentes da produção}

Os efeitos dos tratamentos na produção e em seus componentes foram analisados considerando-se a safra total. A análise de variância (Tabela 3) foi significativa para os diferentes regimes hídricos, ou seja, as produtividades total (PT) e comercial (PC), número de frutos total por planta (NFT), número de frutos comerciais por planta (NFC), peso de frutos total por planta (PFT) e peso de frutos comerciais por planta (PFC) foram influenciadas pelos regimes hídricos propostos, tendo apenas a característica peso médio de frutos comerciais (PMFC) não sido influenciada pelas diferentes lâminas.

As equações que melhor se ajustaram ao relacionamento entre produtividade e lâmina de água foi uma função quadrática, com $\mathrm{R}^{2}$ de 0,87 para a produtividade total e 0,86 para a produtividade comercial, como podem ser visualizadas na Figura 4. O ponto de máxima produtividade ocorreu no maior regime hídrico de irrigação $(1,37 \mathrm{ETo}=601,05 \mathrm{~mm}$ de irrigação $)$ correspondendo a uma produtividade máxima de 13,9 e 12,6 $\mathrm{t}$ ha ${ }^{-1}$ para a total e comercial, respectivamente. Esse regime considerado ótimo, proporcionou aumento de $120,14 \%$ na produtividade comercial em relação à condição não irrigada e os regimes $0,44,0,55,0,86$ e 1,00 da ETo superaram a condição não irrigada, em $68,28,91,12,97,16$ e 84,90\%, respectivamente.

Os rendimentos médios apresentam resultados superiores à média nacional estimada, segundo Pimentel (2000) em 9,67 tha ${ }^{-1}$, correspondendo a um aumento de 44,1 e 29,2\% acima da média de rendimento da cultura no Brasil, para as produtividades total e comercial, respectivamente. Ressalta-se que essas produtividades correspondem ao primeiro ano de colheita na área.

Nos estádios compreendidos entre a floração e a colheita, a deficiência no suprimento ao solo das necessidades de água da mangueira acarreta significativas perdas na produção. Este fato explica o menor rendimento alcançado no tratamento sem irrigação, ao contrário do que ocorreu nos tratamentos irrigados, o que demonstra a necessidade de irrigação nesta região para a manga, onde ocorre déficit hídrico no solo nos estádios compreendidos entre a floração e a colheita, mesmo em se considerando níveis de precipitação total anual de $1654 \mathrm{~mm}$, como foi o caso. Os resultados também indicam, através da análise da curva de resposta que, possivelmente, aumentando os níveis de irrigação, não haverá resposta favorável no
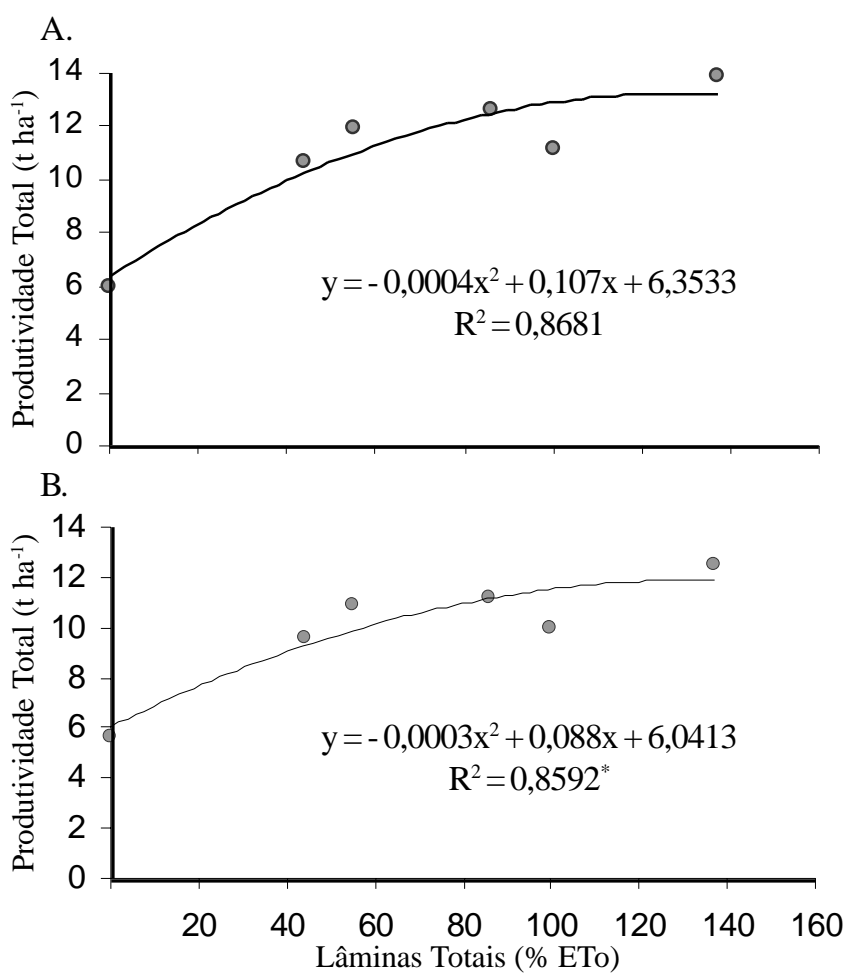

Figura 4. Efeito dos diferentes regimes hídricos na produtividade total (A) e comercial (B) da mangueira

aumento do rendimento de frutos, visto que os níveis de umidade correspondentes à máxima produtividade estão próximos e até acima da capacidade de campo, para a profundidade de $0,70 \mathrm{~m}$. Assim, quantidades de água de irrigação maiores que 1,37 ETo deverão elevar a umidade do solo para valores acima da capacidade de campo, causando problemas de arejamento do solo.

Considerando-se o número de frutos totais e comerciais por planta, as funções de ajuste dessas variáveis à lâmina de água foram também quadráticas, com valores máximos para a reposição de 1,37 ETo. O tratamento que não recebeu irrigação apresentou a menor média de frutos total $(111,9)$ e comercial $(103,6)$ por planta (Tabela 2$)$, o que leva a se afirmar que a aplicação de água suplementar proporcionou condições favoráveis ao pegamento dos frutos (Fig. 5).

O comportamento das variáveis peso de fruto total e comercial em relação às lâminas de irrigação aplicadas, seguiu também a tendência quadrática (Fig. 6) com máximos valores dessas variáveis para a lâmina de irrigação correspondente a 1,37 ETo.

Assim, fica evidente que, da floração à colheita, que corresponde à fase produtiva (diferenciação e crescimento do 
A.

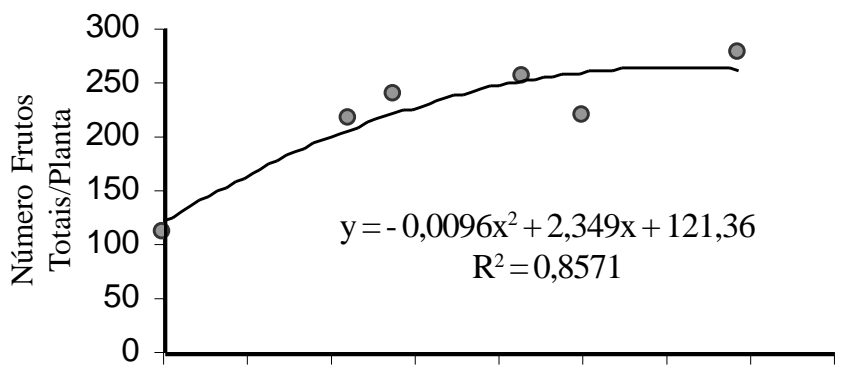

B.

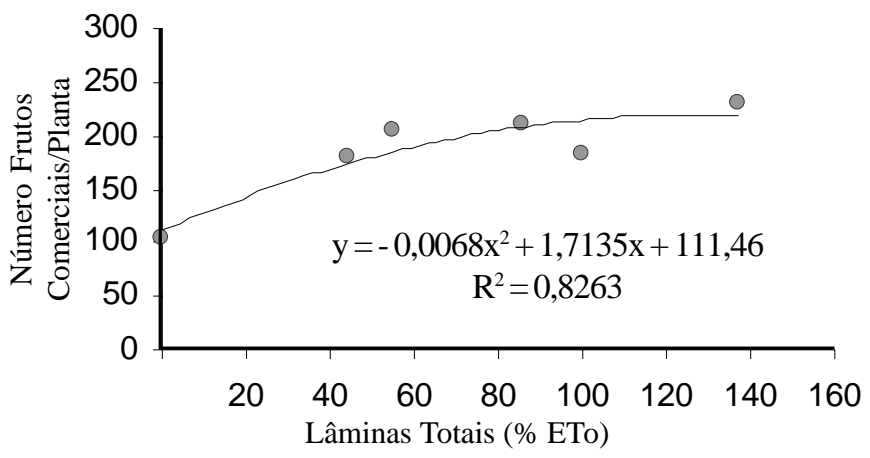

Figura 5. Efeito dos diferentes regimes hídricos no número de frutos total (A) e comercial (B) por planta

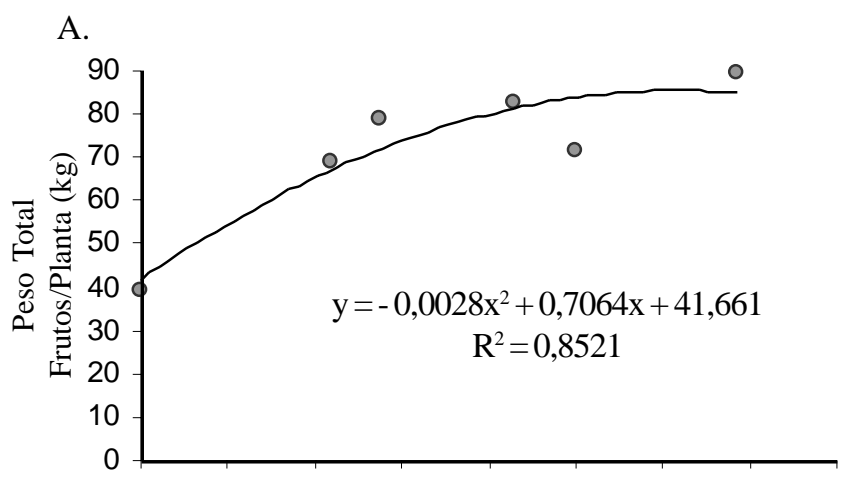

B.

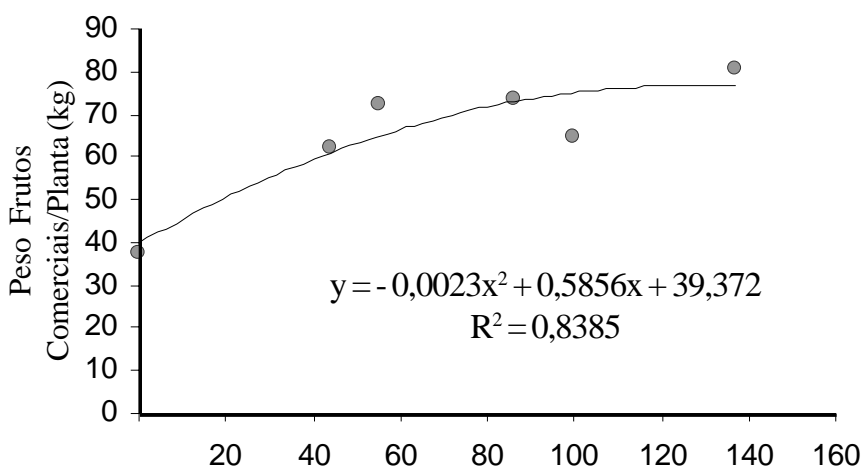

Figura 6. Efeito dos diferentes regimes hídricos no peso de frutos total (A) e comercial (B) por planta

fruto) a deficiência hídrica causa redução na produção de matéria seca, possivelmente em consequiência da redução na translocação de carboidratos provocando, conseqüentemente, redução no número e no peso de frutos na planta.

Com relação ao peso médio dos frutos comerciais (Tabela 3), não houve diferenças estatísticas entre os tratamentos, variando o peso dos frutos de 332,4 a 348,6 g tendo havido, portanto, uma compensação favorável ao ganho de peso dos frutos das plantas que receberam as menores lâminas de irrigação, em função das suas menores cargas de frutos, conforme as características de número e peso de frutos, discutidos acima.

De acordo com Fonfria et al. (1996) quanto maior o número de órgãos em crescimento, maior é a competição entre eles, tanto por elementos minerais como por produtos de fotossíntese, o que limita as suas possibilidades de crescimento e, por conseguinte, o seu peso final. Assim, o peso total da colheita por planta está relacionado ao número de frutos por planta; entretanto, o tamanho individual do fruto está inversamente relacionado ao número de frutos por árvore.

Esses valores estão dentro da faixa estabelecida por Nunes (1995) para o peso médio dos frutos dessa variedade, que é de 300 a $700 \mathrm{~g}$, porém abaixo do valor estabelecido por Albuquerque et al. (1999) que é em torno de $550 \mathrm{~g}$, embora esse autor afirme que, com produtividade alta, este peso seja menor.

\section{CONCLUSÕES}

1. A reposição de água ao solo com base em $137 \%$ da ETo, resultou nos valores máximos físicos das produtividades total e comercial, apresentando maiores valores para número e peso de frutos totais e comerciais por planta.

2. Houve compensação favorável de ganho de peso dos frutos da mangueira pelos tratamentos que receberam menos água e pela condição não-irrigada.

\section{LITERATURA CITADA}

Albuquerque, J.A.S.; Mouco, M.A.C.; Medina, V.D.; Santos, C.R.; Tavares, S.C.C.H. O cultivo da mangueira irrigada no semi-árido brasileiro. Petrolina, PE: Embrapa Semi-Árido/ VALEXPORT, 1999.77p.

Azzouz, S.; El-Nokrashy, M.A.; Dahshan, I.M. Effect of frequency of irrigation on tree production and quality fruit of mango. Agricultural Research Review, Gainsville, v.55, n.3, p.59-66, 1977.

Böhm, W. Methods of studying root system. Berlin: SpringerVerlag, 1979. 188p.

CODEVASF, Compainha de Desenvolvimento do Vale do São Francisco (Brasília, DF). Exportação de frutas brasileiras. Brasília, DF: 1989.352p.

Coelho, E.F.; Borges, A.L.; Sousa, V.F.; Netto, A.O.A.; Oliveira, A.S. Irrigação e fertirrigação da mangueira. Cruz das Almas, BA: Embrapa Mandioca e Fruticultura, 2000. 26p. Circular Técnica, 39

Cunha, G.A.P.; Sampaio, J.M.M.; Nascimento, A.S.; Santos Filho, H.P.; Medina, V.M. Manga para exportação: aspectos técnicos da produção. Brasília: Embrapa-SPI, 1994.35p. Série Publicações Técnicas FRUPEX, 8

Fonfria, M.A.; Ferrer, M.J.; Orenga, V.A.; Romero, V.E.; Alcaina, M.A. Laranja, limão e tangerina: técnicas comprovadas para a produção de frutos de primeira qualidade (aumento de tamanho, do peso e melhoria da qualidade). Porto Alegre: Cinco continentes, 1996. 102p. 
Jensen, M.E.; Burman, R.D.; Allen, R.G. (ed.) 1990. Evapotranspiration and irrigation water requirements. ASCE manuals and reports on engineering practice No. 70. American Society of Civil Engineers, New York, 332p.

Keller, J.; Bliesner, R. Sprinkle and trickle irrigation. New York: van Nostrand Reinhold, 1990. 652p.

Nunes, R.F.M. Práticas culturais e implantação do pomar. In: Embrapa/CPATSA. Informações técnicas sobre a cultura da manga no semi-árido brasileiro. Brasília: Embrapa - SPI, 1995. p. 9-40.

Pimentel, C.R.M. Oportunidades e barreiras à expansão do comércio internacional para a manga nordestina. Revista Econômica do Nordeste, Fortaleza, v. 31, n. 2, p. 166-176, 2000.

Póvoa, A.F.R. Irrigação da mangueira. In: São José, A.R.; Souza, I.V.B.; Martins Filho, J.; Morais, O.M. (coord.). Manga: tecnologia de produção e mercado. Vitória da Conquista: Universidade Estadual do Sudoeste da Bahia, 1996. p.98-105.
Soares, J.M; Costa, F.F. Irrigação. In: Embrapa/CPATSA. Informações técnicas sobre a cultura da manga no semi-árido brasileiro. Brasília: EMBRAPA - SPI, 1995. p.41-80.

SUDENE. Dados pluviométricos mensais do Nordeste - Estado do Piauí. Recife, 1990. p.75-76. Pluviometria, 2

van Genuchten, M.T. A closed-form equation for predicting the hydraulic conductivity of unsaturated soils. Soil Science Society of America Journal, Madison, v.44, p.892-898, 1980.

Vasconcelos, L.F.L.; Veloso, M.E.C.; Araújo, E.C.E.; Coelho, E.F.; Souza, V.A.B. Evolução da mangicultura no estado do Piauí. Teresina: Embrapa Meio-Norte, 1998. 23p. Documentos, 35

Volpe, C.A.; Churata-Masca, M.G.C. Manejo da irrigação em hortaliças: método do tanque Classe A. Jaboticabal: FUNEP, 1988. 19p. 